\title{
ONOMÁVAEIN
}

Revista semestral de lingüística, filología y traducción

\section{La escritura antigua filipina y la adopción del alfabeto latino para la representación de las lenguas del archipiélago en las artes y ortografías de la tradición misionero-colonial española ${ }^{1}$}

Philippine ancient writing and the adoption of the Latin alphabet to represent the languages of the archipelago in the arts and orthographies of the spanish colonial missionary tradition

\section{Miguel Cuevas Alonso \\ Universidad de Vigo \\ España}




\section{Resumen}

En este trabajo pretendemos sacar a la luz el tratamiento que de los métodos escriturales que servían para representar las lenguas de Filipinas antes de la llegada de los españoles realizan los misioneros en su proceso de gramatización de dichas lenguas. Tras el estudio pormenorizado del modo en que se recoge la tradición escritural filipina en un gran número de obras gramaticales misioneras, nos centraremos en los aspectos que determinaron la adopción del alfabeto latino, el modo en que este es usado por los misioneros para representar las lenguas filipinas y las estrategias que debieron utilizar para salvar los problemas que el uso de este abecé presentaba en su aplicación a esas realidades lingüísticas.

Palabras clave: historiografía lingüística; Filipinas; escritura; tradición gramatical hispánica.

\section{Abstract}

The first aim of this paper to expose the treatment of the scriptural methods used to represent the languages of the Philippines before the arrival of the Spanish colonizers done by the missionary linguists in their gramatization process of these languages. After a detailed study on how scriptural Filipino tradition is treated by a large number of grammatical missionary studies, we focus on the aspects that led them to the adoption of the Latin alphabet, how it is used by the missionaries to represent Filipino languages and what were strategies that should be used to circumvent the problems that the use of this alphabet presented in its application to these linguistic realities.

Keywords: Linguistic Historiography; Philippines; writting systems; Spanish grammatical tradition.

1 Este trabajo se ha realizado parcialmente en el marco del proyecto Lingüística española en Asia (fase I), financiado por el Ministerio de Economía y Competitividad y con referencia FFI2010-19944. 


\section{Introducción}

Se puede afirmar que en la tradición gramatical la escritura no es un fin en sí mismo sino que debe estar en consonancia con su propósito: la representación de los elementos fónicos de las lenguas. Así, señala Abercrombie que "when constructing any system of visual symbolization of speech, convenience must be in the long run be the only guide, and practice, not abstract logical principles, the only valid test" (Abercrombie, 1965a: 91) y, por consiguiente, "a notation having a consistent relation to pronunciation is useful also for more popular needs, such as pronouncing dictionaries, grammars, and foreign language textbooks" (Abrecrombie, 1981: 207).

En este trabajo nos planteamos dos objetivos. El primero de ellos es analizar el modo en el que los misioneros trataron los sistemas escriturales que existían en Filipinas con anterioridad a la llegada de los españoles, y el segundo, abordar la necesaria adaptación del alfabeto latino para representar las lenguas filipinas y su generalización en detrimento de los caracteres silábicos preexistentes.

De este modo retomamos aquí una idea de Abercrombie, que cobra especial importancia cuando los historiógrafos nos acercamos a los textos lingüísticos previos al surgimiento de la fonética y la fonología tal y como las entendemos en la actualidad. Para este autor "there is, in fact, a firm opinion in some quarters that before about 1830 there was no such thing as phonetics. There was no such word, it is true; but something very like the thing has existed for a long time" (Abercrombie, 1965b: 45). En el caso que nos ocupa, la importancia de esta cuestión rebasa los límites de la búsqueda de adecuación entre sonidos y letras, ya que establece claros vínculos con el sistema (o sistemas) escritural(es) presente(s) a la llegada de los españoles al archipiélago filipino y con la elaboración de una descripción por contraste con las lenguas conocidas por los mi- sioneros, necesaria para los fines propedéuticos y evangelizadores que perseguían (Cuevas Alonso, 2011).

Si bien el estudio de Abercrombie se centra en lingüistas ingleses de los SS. XVII a XIX, bien pueden aplicarse sus afirmaciones, mutatis mutandis, a los misioneros gramáticos españoles. Estos se sienten obligados a describir las lenguas de las colonias para que los ministros recién llegados a ellas las aprendan y puedan evangelizar, integrarse en la sociedad y conocer la cultura de aquellas tierras. Pero tal empresa no es fácil y han de enfrentarse a la consideración de las unidades fónicas de lenguas tan diversas a partir del contraste con sus lenguas maternas y, aunque no realizan una descripción fonética exhaustiva, reconocen aquellos elementos fónicos cuya conmutación produce cambios en el significado y son capaces de señalar la distribución contextualmente condicionada (específica o no, con o sin alternancia). Existirá una notable preocupación por el modo en que las grafías representan la lengua hablada y por la necesidad de evitar divergencias entre escritura y pronunciación. Es en algunos de estos casos en los que el silabario que los religiosos encuentran a su llegada a las islas sirve de referencia.

El corpus con el que hemos trabajado ( $v$. "Fuentes primarias") consta de quince artes misionero-coloniales de Filipinas y una ortografía, la única que hemos podido localizar, de los siglos XVII y XVIII. Si toda muestra es deudora de la población a la que pretende representar y en nuestra investigación hemos intentado dar cabida a un número considerable de gramáticas, es obvio que esta ha de reflejar en cierto modo el peso que las diferentes lenguas tuvieron en la gramatización de la zona. Destacan por su número las gramáticas del tagalo y bisaya, seguidas muy de lejos por las del ilocano, el bicol y el pampango. Además, las artes seleccionadas no solo son representativas de las lenguas más utilizadas en aquella época en el archipiélago filipino sino 
que se trata, con diferencia, de los trabajos más elaborados y reflexivos. Estas, sin llegar a constituir un corpus estrictamente especulativo, se separan en su concepción de otras muchas meramente didácticas o escolares.

Con respecto al período temporal, nos hemos centrado en la etapa que Sueiro Justel (2002b) denomina propiamente misionera, esto es, hasta finales del s. XVIII. Se caracteriza por que la totalidad de los artígrafos, con raras excepciones, son religiosos y por un escaso interés de la Administración y de los colonos por las lenguas filipinas. Frente al predominio absoluto de artígrafos pertenecientes a las diversas órdenes religiosas o al clero secular en los Ss. XVII y XVIII, durante el S. XIX se constata la presencia de gramáticos civiles que no tienen intereses científicos, religiosos, históricos o antropológicos ni, tampoco, fascinación por el contraste entre lenguas, las interferencias que puedan darse entre ellas, etc. Se trata de profesores, abogados, militares, etc., cuyo objetivo no es otro que afrontar las necesidades comunicativas relacionadas con el comercio, la administración... Este nuevo marco implicará la aplicación de métodos de enseñanza diferentes a aquel que, desarrollado por los religiosos durante la etapa propiamente misionera (Sueiro Justel, 2003: 12), exigía de los aprendices el conocimiento de la gramática latina y que se basaba en la reglamentación de la lengua, procedimiento éste de clara procedencia quintiliánica.

Un segundo criterio de selección de obras ha tenido en cuenta el objetivo último de las artes y la metodología que emplean. Así, durante la primera etapa, estas tienen como fin la enseñanza de la lengua en un contexto de inmersión lingüística. Lo que pretenden fundamentalmente es servir al aprendizaje de la lengua para extender el Evangelio. Puesto que los destinatarios de dichas obras son religiosos conocedores de la lengua y la gramática latina, se parte del modelo de gramática latina de Nebrija con las varia- ciones e innovaciones necesarias para someter a arte lenguas tan diferentes (v. Cuevas Alonso, 2011 y Sueiro Justel, 2003: 13 y ss.).

En este trabajo compararemos el modo en el que se aborda la cuestión del silabario en las diferentes artes y analizaremos en profundidad cómo fue el proceso de sustitución de este por el alfabeto latino. Comenzaremos por describir brevemente el proceso gramatizador que se produjo en el caso de las lenguas filipinas (apartado 2) para continuar con el análisis del modo en que los sistemas escriturales de las islas aparecen reflejados en las obras misioneras filipinas (apartado 3) para, a continuación, abordar el modo en que adoptó y se debió modificar el alfabeto latino para representar las diversas lenguas (apartado 4). Finalmente, en el apartado 5 señalaremos las conclusiones más relevantes.

\section{La codificación de las lenguas filipinas}

El interés por textos de carácter lingüístico realizados en las colonias radica fundamentalmente en que su estudio nos ayuda a comprender numerosos aspectos del proceso gramatizador que surge durante el Renacimiento en Europa y que se extiende a las colonias, amerindias y filipinas para el caso de la tradición española. Estas obras tienen su lugar en la Historia de la Lingüística y son herederas de un entorno epistemológico concreto en el que el latín y la lengua vernácula del misionero se constituyen en lenguas de referencia, eslabones, sin ser una corriente filológica (Esparza, 2010), necesarios para la lingüística posterior (v. Breva Claramonte, 2008).

A falta de una tradición gramatical autóctona en los nuevos territorios o por afán pedagógico (García Medall, 2010: 208) son las Introductiones de Nebrija, en su edición recognitio, las que se configuran en el modelo de los artígrafos para construir las artes destinadas al aprendizaje de las lenguas indígenas, aquellas que debían ser 
sometidas a reglas, como había sido demostrado ya para las lenguas europeas (Swiggers y Vanvolsem, 1987: 161). Es precisamente en este proceso gramatizador en el que se insertan plenamente las obras analizadas en este trabajo.

No entraremos a continuación a retomar aspectos sobre la gramatización de las lenguas amerindias y filipinas, ya que han sido tratados con exhaustividad en trabajos de otros investigadores (véase, entre otros, Suárez Roca, 1992; Zwartjes (ed.), 2000; Sueiro Justel, 2002a,b,c,d, 2003; Cuevas Alonso, 2011, y, sobre la importancia de las lenguas generales, Altman, 1999; Sueiro Justel, 2002b,c, 2003). No obstante, se debe señalar que la creación de las gramáticas se debe al fin último de la evangelización y al mantenimiento de las cuotas de poder establecidas. De este modo, los religiosos eran partidarios de la evangelización de los indios desde la lengua de estos, independientemente de las directrices llegadas desde la administración. Así se aseguraban de la ortodoxia en la transmisión de la doctrina de la Iglesia y de que no existía el peligro de que sus puestos y privilegios fueran ocupados por sacerdotes procedentes de la metrópoli, habida cuenta de que su desconocimiento de la lengua restringía (incluso eliminaba) la posibilidad de comunicarse con los indígenas (v. Guzmán de Betancourt, 1997).

Durante la presencia española en Filipinas se produjo un proceso en el que las lenguas más habladas en las islas adquirieron una mayor importancia, con la simplificación de la enorme variedad existente (Sueiro Justel, 2002c: 9-30; 2002b: §4.1 y \$4.2; 2003: §3.2; Quilis y Casado, 2008: §1.4). Pero no fueron estas las únicas en ser gramatizadas, sino que muchas lenguas minoritarias también ocuparon el interés de los misioneros.

Por otro lado, la política lingüística tampoco fue idéntica en América y Filipinas, aunque en el caso de las islas orientales se parte de la experiencia que ya se tenía de las colonias americanas. El Consejo de Indias repartió los territorios entre las diversas órdenes religiosas de la forma más equitativa posible: según el número de habitantes, su importancia económica y estratégica, etc. Sin embargo, esta división no se respetó en numerosas ocasiones y dio lugar a desacuerdos entre las órdenes regulares por la importancia de los territorios (v. Phelan, 1959: 50-51).

Como se ha señalado con anterioridad, la gramática latina de Nebrija se convierte en el molde por el que los misioneros se guían en su sometimiento a arte de las lenguas. Es, por así decirlo, el origen de toda la tradición gramatical misionero-colonial de origen hispánico (v. Suárez, 2007, y Hernández de León, 2007). Esta constituía la gramática de referencia para los seminaristas que necesitaban aprender latín, y los misioneros aplicaron su conocimiento al servicio de la gramatización de lenguas (ligado a un proceso de transculturación [v. Auroux, 1994: 120 y ss.]) que no les eran familiares, lo que les confería su estatuto de lenguas con pleno derecho (v. Moreno Fernández, 1994: 85, y Esparza, 2007). No obstante, las bases de la gramatización se adaptan al material real de las lenguas que se pretenden someter a arte y las categorías de la descripción irán perdiendo su identidad conceptual y su vinculación a una lengua concreta para emplearse en la descripción de lenguas muy diversas en función de la asignación de diferentes propiedades (v. Cuevas Alonso, 2011: cap. 3). Así pues es rara la aplicación directa de la gramática latina, puesto que en la mayor parte de las ocasiones esta era tamizada por las características de la lengua que se pretendía describir (Bustamante, 1987: 84), no se aplica sin reflexión sino que se buscan formas (en ocasiones nuevas, en ocasiones a partir de transformaciones) que expliquen lo más adecuadamente para la época la realidad gramatical a la que se enfrentan (Suárez Roca, 2000: 78).

Este proceso gramatizador a gran escala, que abarcó Europa, América y Asia, a partir de una tradición gramatical y calificado como el de- 
sarrollo de un proyecto lingüístico europeo por Oesterreicher y Schmidt (1999: 72) en el marco de un "proyecto no lingüístico" en América y Asia: la evangelización (Zimmermann, 2004: 22-23), es único en la historia de la lingüística por su extensión e importancia e incomparable cuantitativa y cualitativamente a fenómenos de gramatización previos. Según la hipótesis de Auroux (1994), este constituye una revolución tecnológica similar a la invención de la escritura, que modificó la ecología de la comunicación y que revela la unidad de la tradición europea que "dans son état contemporain cette tradition est un état de savoir à prétention universelle" (Auroux, 1994: 68). Esto hizo que la gramática se conviertiera en una técnica de enseñanza, por un lado, y de descripción de la lengua, por otro, lo que favorece la idea de que cualquier lengua puede ser objeto de gramatización (ibíd.: 73-77).

\section{Referencias a los silabarios en las ar- tes misioneras de Filipinas}

En el contexto anteriormente descrito, los misioneros se enfrentaron a su llegada a América y a Filipinas con una situación no poco problemática. Se encontraron con sistemas de escritura que presentaban características completamente diferentes a las del alfabeto latino. Además, en el caso particular filipino constataron la existencia de un silabario propio de origen indonesiomalayo que contenía caracteres procedentes del sánscrito y cuya descripción podemos encontrar en documentos tempranos, como en el siguiente texto de Morga de principios del s. XVII:

La lengua de todos, los Pintados y Biçayas, es una mesma, por do se entienden, hablando y escriviendo, en letras y carateres que tienen particulares, que semejan a los Arábigos (Morga, 1997 [1609]: 273)

Todos los gramáticos que hacen referencia a estas grafías silábicas las denominan letras. Sin embargo, encontramos una excepción. Pedro Andrés de Castro se refiere a ellos en numerosas oca- siones con el término "caracteres" (Castro, 1776); en otras, utiliza palabras o expresiones como "letras" (Castro, 1776: 11), "trahen pintados los Caracteres Tagalos" (Castro, 1776: 12) o "su modo geroglifico, y simbolico" (Castro, 1776: 19), etc.

A diferencia de los intentos más o menos circunstanciales que hubo en América de tratar de hibridar los dos sistemas de representación o de, al menos, utilizar parcialmente alguno de los amerindios con el fin de no retrasar la evangelización (v., entre otros, Acker, 1994/1995; Borrero Barrera, 2002, y Arzapalo Marín, 2005), en Filipinas no parece que se produjera tal acercamiento a los sistemas de representación de los naturales. Es verdad que en un primer momento se consideró la necesidad de conocer la escritura de las islas como procedimiento para aprender mejor las lenguas pero, en poco tiempo, los misioneros se contentaron con establecer las equivalencias entre el alfabeto latino y el sistema de escritura de los nativos o ya, directamente, con prescindir de él y dejar constancia de su desaparición y de la extensión del sistema de escritura que ellos mismos habían introducido.

En las gramáticas misionero-coloniales de Filipinas encontramos solamente referencia a la diversidad de caracteres en función de las lenguas o variedades dialectales en dos de las obras analizadas. En su Ortografía tagala, Castro (1776) observa que las letras varían de isla en isla y advierte al lector de que utilizará los que se emplean en la corte de Manila, por ser el lugar al que van a estudiar los jóvenes de las islas:

si acaso vieres en el Arte del Padre Fray Francisco de San Joseph ù de otros, algunos Caracteres distintos de los que aqui pongo siguiendo a Fray Gaspar, no hagas caso de ellos, porque son peculiares dela Provincia de Batán, y montes de Sambales, y solo alli se usan. Muy bien saben los curiosos que cada Provincia de esta Isla de Luzon, tenia diferentes Caracteres, y diferente Idioma: y aun en una misma lengua Tagala $v$. g. hay diferentes modos de hablarla y de escribirla, como lo 
he visto en la Comintan, y en los Tingues de San Pablo, en Mindoro, y en Marinduque. Pero los que aquí te pongo, son los usados en la Corte de Manila, a donde vienen a estudiar muchachos de todas las Islas Filipinas (Castro, 1776: 64).

Algo más escueta y marginal es la observación Andrés López en su gramática pangasinana:

y esto aunque este [la g gangosa] al remate de la diccion lo, qual colijo claramente de la pronunciacion, y modo de escriuir los indios en sus caracteres, que los tienen distintos de los Pampangos y Tagalos, pero ya ay muy pocos que los entiendan (López, 1690: fol. 3-3V).

No obstante, no todos los gramáticos concuerdan con las observaciones de Castro y de López. En la gramática pampanga de finales del s. XVII, Benavente nos da noticia de la filiación que los caracteres tienen entre sí, no sólo al asumir un origen malayo ${ }^{2}$, sino también al afirmar que estos son comunes a todas las lenguas de las islas:

No trato del modo de escribirla lengua Pamp[ang] a con los caracteres malayos comunes a todas las de este archipielago o que en Pamp[ang]a dicen culit. Mas para enterarnos bien del modo con q. se debe escrivir con los nuestros, discurrire por aquellos (Benavente, 1699: fol. 8).

Por su parte, Oyanguren de Santa Inés, en su Tagalysmo Elucidado, atribuye el origen malayo al silabario y reconoce explícitamente la diferencia con las letras hebreas, griegas, árabes, etc. Es consciente del carácter silábico del sistema al observar cómo las vocales se indicaban mediante puntos:

Los Malayos, y Tagalos tuvieron letras consonantes proprias como se vè en algunas Escrituras, y Testamentos antiguos; para las vocales se valian de dos puntos puestos, ó à la parte superior, ò à la parte de abaxo; de que algunas veces resultaba duda; estas letras en su forma son distintas de las Hebreas, Griegas, Arabes, Macoas, Chinicas, Gothicas, como se puede vèr en el peritissimo P. Fr. Gaspar de San Augustin (Oyanguren, 1742: 3-4)

Una vez que hemos visto cuál es el origen atribuido a los sistemas escriturales filipinos por los artígrafos misioneros, hemos de señalar que solo algunos de ellos incluyen en sus descripciones la correspondencia entre estos y el alfabeto latino. En los casos en que aparece, esta obedece en un primer momento a la preocupación que los primeros misioneros tienen por adaptar un sistema ideográfico/pictográfico (en algunos casos americanos, como en el caso de los zapoteco, mixteco, maya y azteca) o silábico (en Filipinas) desconocidos a otro, el alfabeto latino, que tenía ya fijada la relación letra-pronunciación y con el que estaban familiarizados. Dadas estas diferencias, en Filipinas no parece que se hiciera necesario un proceso de literalización (transcripción, conceptualización de la letra y normalización ortográfica) (v. Horta Nunes, 1993) como el que se había producido, por ejemplo, en América.

Asumir el alfabeto latino en detrimento del silabario les permitía acelerar el proceso de aprendizaje y centrar su descripción en la pronunciación de las unidades que se desviaban con respecto de las del español o del latín y en aquellas otras que no estaban presentes en el inventario de las lenguas de referencia por sus características fónicas. Con esta impronta pedagógica y como sucediera en las gramáticas americanas (Díaz Rubio y Bustamante García, 1986), el criterio parece ser la máxima quintiliánica: escribir como se pronuncia y pronunciar como se escribe.

Sin embargo, muchas gramáticas no hacen referencia al sistema escritural previo a la llega-

2 P. A. de Castro (1776: 11) indica que el origen de la escritura filipina se encuentra en los malayos, como Benavente, pero añade una filiación histórica que se remonta aún más atrás y afirma que "estos Malayos tomaron sus letras y Caracteres delos Arabes; y estos delos Siros, o Asirios. Delo qual se colige con evidencia, la antiguedad, excelencia, y nobleza de nuestra Tagala". Como vemos, se trata de un evidente intento de dignificar la lengua y de vincularla, a través de la escritura, a la lengua primigenia.

3 Un texto similar lo encontramos también en P. A. de Castro (1776: 65) 
da de los españoles a las islas Filipinas. Son casos que o nos ofrecen una brevísima noticia de la pronunciación o que parten ya de que se ha producido la sustitución de un sistema por otro. $Y$ es que muy pronto los gramáticos constatan en sus artes que el alfabeto latino está ya generalizado en las islas, lo que conllevó el abandono del sistema escritural tradicional.

El factor determinante de la rápida implantación del abecedario para transcribir las lenguas amerindias y filipinas lo encontramos en la educación infantil. En su Historia de los Indios de la Nueva España, fray Toribio de Montolinía observa que los nativos americanos aprendían rápido los oficios y la escritura. Dice refiriéndose a un niño de la escuela:

En el segundo año que les comenzamos e enseñar dieron a un muchacho de Tetzcoco por muestra una bula, y sacola tan a lo natural, que la letra que hizo parecía el mismo molde [...] todo tan al propio, que parecía no haber diferencia del molde a la otra letra (Montolinía, 1541: 206).

También en Filipinas, los centros educativos se convierten en el gran ente difusor de los caracteres latinos que sustituirán a los que eran utilizados de forma generalizada en el archipiélago. Así lo explica Oyanguren:

Oy dia se van olvidando de estas letras, porque los Españoles introdujeron las letras Gothicas, y los Operarios Evangélicos ayudan con incessante desvelo, manteniendo en cada Pueblo su Escuela (Oyanguren, 1742: 3-4).

Un buen ejemplo de este proceso de olvido del sistema escritural podemos ofrecerlo al contrastar las noticias que de él nos dan las gramáticas analizadas para este trabajo. En el tagalismo de San José encontramos la recomendación de que los religiosos aprendan el silabario con el objetivo de no errar en la pronunciación:

ALGVNAS VEZes junto a la palabra Tagala escrita en letras Españolas se ponen las letras Tagalas con que se escriue la misma palabra: para que por ellas conozca quien las sabe leer la pronunciacion que se le deue [...] debrian los que dessean hablar medianamente bien, aprender la lectura de las letras Tagalas, pues es cosa tan facil, que en vna hora es ordinario aprenderse: no obstante que el leer expeditamente la lengua Tagala en sus mismos Characteres como leemos nuestra lengua Española, no lo aprendera ningun Español en toda la vida aunque sea tan larga como la de Adan [...] por que al cabo y a la postre leer su letra es medio adiuinar. Con todo esto ruego al curioso que aprenda la dicha lectura: y vera como le ayuda para la perfecta pronunciación (San José, 1997 [1610]: 2).

Hemos de constatar el parecido de esta afirmación de Blancas de San José con el planteamiento de Nebrija: "algunas lenguas tienen ciertas bozes: que los ombres de otra nacion: ni aun por tormento no pueden pronunciar" (Nebrija, 1492: fol. 6v). Es aquí donde entra en juego la premisa de adaptación al uso, es decir, acudir al indígena, escuchar y reproducir.

Pero será Castro en su Ortografía quien justifique razonadamente, apoyándose en la propia naturaleza de la lengua (que incluye el sistema escritural) y la natural (divina) relación entre sonido y letra, la necesidad de aprender los caracteres. Como vemos en el fragmento que presentamos a continuación, su propuesta está en comunión con el espíritu de la época:

Ello es certissimo é indubitable apud omnes: que los Caracteres propios de una lengua no pueden servir para otra, si primero no los alteran y adulteran. Como podran representar la entera, natural, y propria pronunciacion, fuera de su [?] y pais? No han visto muchas veces que los rabanos. y otras legumbres en Castilla, plantadas en Filipinas, degeneran en nabos? Pues lo mismo sucede con los Camotes de Filipinas, plantados en España, que luego se convierten en otra cosa muy diferente [...] Y assi digo resueltamente con la autoridad de Quintiliano, que ni el griego se puede escrivir en letra latina; ni el latin en la Griega [...] 
Y assi, como viejo experimentado te aconsejo menos cruces 4 y mas Christos: esto es, que procures estudiar sus Caracteres y entenderlos tal qual lo que pudieres; pues aunque sea poco, te ha de valer mucho para entender la lengua (Castro, 1776: 16-18)

Castro defiende, como Blancas, la utilidad de conocer la escritura tagala y señala que esta no genera una confusión tan grande como pretenden los gramáticos previos5:

Siete Artes Tagalos hè visto impresos en Manila: un Dominicano, tres Franciscanos, y tres Agustinos y todos hacen grandes aspamientos y admiraciones, de nuestros Caracteres [...] diciendo que esta escritura Tagala es una confusion, y adivinanza toda ella, porque se suplen muchas letras: sin acordarse estos Authores que en su lengua Castellana hay lo mismo y aun mas todavia [añade toda una serie de ejemplos castellanos] [...]

De todo lo qual se infiere que no es tan dificultosa nuestra escritura Tagala y que si los Authores dichos, se hubieran aplicado mas, a entenderla, para explicarla a los nuebos, tuvieramos hoi este camino andado, y los discipulos saldrian por este medio tan facil, mexores lenguaraces é Idiomaticos (Castro, 1776: 69-71).

Será precisamente en su Ortografía donde encontremos una explicación exhaustiva de cómo se escribe en caracteres tagalos. Nota el autor que "aunque un termino pase a ser compuesto y recompuesto muchas vezes, no por esso pierde su modo de escrivirse, que tenia en su simple raiz; sino que siempre lo conserva" (Castro, 1776: 77). Además de las reglas generales de señalamiento de vocales indica en su obra cómo se transcriben los extranjerismos, incluida la cruz bajo el carácter del silabario para indicar la separación silábica por causa de una glotal, que siguiendo la tradición misionera pre- via (amerindia y filipina) denomina "cortadillo", las vocales que conforman sílaba sin la presencia de consonante, las consonantes en posición postnuclear (que "se suplen in mente" [Castro, 1776: 73]), las vocales heridas por otras vocales en diptongo o como semiconsonantes y qué vocales y consonantes se escriben explícitamente y cuáles se suplen y no se escriben.

A finales del XVII, Benavente, en su Arte y vocabulario de la lengua pampanga (c. 1699), aunque establece la correspondencia entre ambos sistemas escriturales, defiende la escritura en caracteres latinos. De la siguiente afirmación parece inferirse una doble razón para aceptar el alfabeto: por un lado existe la necesidad pedagógica de tener un sistema de representación conocido por los destinatarios de las artes $y$, por otro, subyace la idea de que se está generalizando frente al silabario:

No trato del modo de escribir la lengua Pamp[ang] a con los caracteres malayos comunes a todas las de este archipielago o que en Pamp[ang]a dicen culit. Mas para enterarnos bien del modo con q. se debe escrivir con los nuestros, discurrire por aquellos (Benavente, c. 1699: fol. 8).

Ya en el s. XVIII, el misionero Gaspar de San Agustín (1787=1703: 168 y ss.) señala en su Compendio de la Arte de la Lengua Tagala que el modo de "escribir antiguamente" es "tan facil de escribir como dificil de leer, porque es adivinar" y observa que este sistema sólo es utilizado en la provincia de Comintan. En su descripción, como sucediera en la Ortografía de Castro (1776), también indica cómo las vocales se señalan mediante puntos situados encima o debajo de las grafías. La misma explicación la encontramos en la gramática tagala de Ortiz (1740) o en las del bisaya de Méntrida (1818=1637: 245) y Ezguerra (1747=1663: fol. 1r).

4 Se refiere a las que a las que se ponían bajo determinados caracteres del silabario para indicar características concretas de la pronunciación de los filipinos, concretamente de la consonante glotal, a la que denominan comúnmente "cortadilla".

5 No obstante, podemos hacernos una idea de la dificultad que suponía leer los caracteres tagalos si atendemos a las reglas que sobre pronunciación nos ofrece Castro (1776: 69 y ss.). 
También en este siglo, Totanes señala en las advertencias al inicio de la gramática tagala que no trata los caracteres tagalos "porque es yà raro el Indio, que los sabe leer, y rarissimo el que los sabe escribir" (Totanes, 1745: fol. 1) y añade que todos los naturales escriben y leen los caracteres castellanos. No obstante, apenas cinco años antes Ortiz (1740: 120-121) presentaba en su arte tagalo la correspondencia con nuestro alfabeto. Este autor copia la tabla (v. ilustración 1) que había sido reproducida por Gaspar de San Agustín (1787=1703: 168) y que también encontramos en la Ortografía de Andrés de Castro (1776: 67).

Según Quilis y Casado (2008: 318), se trata del primer alfabeto conocido de las islas y aparece recogido por primera vez en la Historia de la provincia de Filipinas de la Compañía de Jesús de Pedro Chirino (1635?). Ambos, San Agustín y Ortiz afirman que la lectura de corrido en caracteres tagalos era prácticamente adivinar. Veamos cómo lo enuncia Ortiz:

En lugar de las Comas, y Puntos Castellanos, ponen dos rayas despues de cada Palabra en esta forma II. Las quales no sirven para mayor claridad, sino para mayor confusion.
La Escritura Tagala es toda ella vna confusion: porque si es dificil de escribir, mucho mas lo es de leer, y de entender (Ortiz, 1740: 121).

A finales del S. XVIII, Andrés de Castro retoma en su Ortografía este texto de Ortiz para señalar que la causa de que los naturales comiencen a escribir en el alfabeto latino se debe a su propio aburrimiento por los problemas de la interpretación del silabario. Se constatan aquí dos cuestiones: 1) que las dificultades que entrañaba el sistema escritural filipino para los españoles se han extendido a los propios naturales y 2) que este cambio se ha producido debido fundamentalmente al peso de la escuela.

Los naturales han ido olvidando su sistema de representación gráfica de la lengua a medida que incorporan el europeo. Llegado un determinado momento, las dificultades en el uso del silabario que tienen los misioneros son trasladadas a la población filipina que, poco a poco, va deshaciéndose de su forma tradicional de escritura. Pese a todo, el ortógrafo reivindicará el silabario para solucionar algunos problemas de pronunciación ocasionados por la transcripción alfabética ${ }^{6}$ :

\section{ILUSTRACIÓN 1}

Silabario según Ortiz (1740: 120)

\section{G}

I bal ca ldaralgal nga I ha I la I ma l na I pafal fal ta I valya I 1 bagl can 1 dap Iganl nğgan I bal langlmanglnangl pat if.anl tap I vallyagl Quando fe les pone vn punto arriba hieren en $J$, ò en $E . V g$. 1 bel que Idereiguel nğge I be I le I nel ine Ipefe lie I te I veI ye I

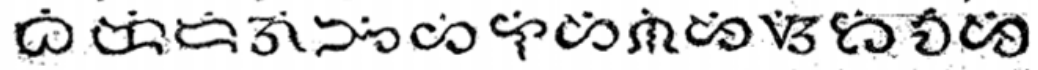

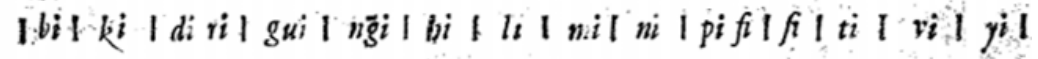
Quando fe les pone va punto abajo hieren en $\mathrm{O}$. V. Vg. lbol coldorol gol nigo I bo 1 lo I mol no l pofol fol tol rol yol Q⿻ न

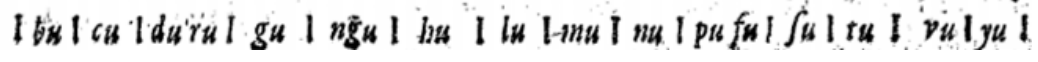

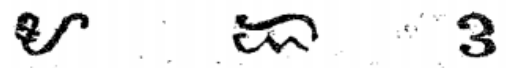

a. e. i. o. u.

ang. in. og.

6 Se puede observar cómo este autor emplea un lenguaje cargado de tintes colonialistas, tratando explícitamente el alfabeto latino como un sistema superior. 
Por esto pues [se refiere a las dificultades que conlleva la lectura de los textos escritos al modo tradicional], y por otras dificultades que diremos, se aburren los mismos Tagalos, y son muy pocos los que saben escribir y menos leer sus Caracteres: por lo qual asi que ellos vieron y entendieron los nuestros, fueron olvidando los suyos proprios, y abrazaron con mucho gusto los nuestros, en los quales han salido muy diestros Pendolistas, bien que defectuosos siempre en la colocacion y eleccion de las letras, por falta de Ortografia, é Idioma (Castro, 1776: 13-14).

Ya en el S. XIX, José Aparicio corrige y aumenta la gramática bisaya de Méntrida. Con la excepción de unas breves notas al final del arte (1818=1637: 244-245) y un apartado dedicado al diptongo en la parte de la poesía (ibíd.: 236-238), en la edición de 1637 Méntrida no había dedicado espacio a la pronunciación y a las letras de esta lengua y comenzaba su gramática con la descripción del nombre. En la edición de 1818, Aparicio añade una serie de advertencias; la primera de ellas la dedica al alfabeto y la pronunciación. En ella señala ya la práctica desaparición del uso del sistema escritural filipino:

Parece ser que antes tenian los antiguos bisayas alfabeto especial con caracteres de distinta configuración ó forma de la de nuestras letras, pero hoy día nadie conoce aquellos caractéres, y solo usan del alfabeto y caractéres castellanos, excepto algunas letras (Méntrida, 1818: vii).

Dicho esto, si retomamos la descripción que realiza Ortiz, probablemente la nota más relevante sea que este afirma el carácter silábico del sistema escritural utilizado en Filipinas con mayor claridad y precisión que cualquiera de las otras gramáticas analizadas. En estas últimas apenas encontramos alusiones a la sílaba. Sin embargo, Ortiz la utiliza precisamente como referencia en la descripción de la pronunciación. En su explicación aparece señalada la relación entre la sílaba y su reflejo gráfico y se percata de la diferencia existente con el sistema alfabético. Nos muestra su funcionamiento, describe el modo de señalar las vocales $y$, probablemente sin ser consciente de ello, las estructuras silábicas más comunes en la lengua que se dispone a gramatizar (V, CV, CVC):

Los Caracteres Consonantes sirven para Sylabas enteras, que tienen Consonante en el principio, y en el fin Vocal, ò en el intermedio Vocal, y en el fin Consonante. Quando los Caracteres se ponen desnudos? entonces dicen la Vocal A. Quando se pone vn punto arriba de ellos, dicen las Vocales I, y E. Quando se pone el punto abajo dicen las Vocales O. y V (Ortiz, 1740: 120).

El agustino parte de los caracteres tagalos para describir los sonidos en la lengua y nos ofrece notas muy interesantes sobre el modo en que eran usados. Nótese, por ejemplo, que establece una clara distinción entre lo que se escribe y aquello que se pronuncia y la vinculación entre el silabario y el alfabeto latino; plantea así una oposición caracteres/letras que, sin embargo, queda diluida al hablar de las consonantes, donde aparecen como sinónimos, a partir del servicio de los primeros a las segundas. Esta explicación podría tener su fundamento en dos aspectos: 1) el doble significado de "letra" como grafema y sonido, procedente de las tradiciones europea y amerindia previas, y 2) la consideración del alfabeto latino como superior? . En definitiva, parte del abecé procedente de Europa y señala las carencias del silabario. También indica este misionero el modo en que pueden aparecer tales caracteres. Veamos el ejemplo de las vocales:

Los [caracteres] Vocales, que para escribir son tres, para hablar son cinco, porque vsan independientemente de la $E$, y de la I, como si fuéssen vna misma cosa. Lo mismo sucede con la $O$, y con la $V$. Los Caracteres Vocales sirven para las Letras Vocales solas, y también para las Sylabas compuestas de Vocal en el principio, y de Consonantes en el fin (Ortiz, 1740: 119). 
Para concluir este apartado, se ha de señalar que también hallamos en estas obras referencias a la disposición y a los soportes materiales de la escritura. En este sentido, la gramática bisaya de Ezguerra nos ofrece un retrato clarísimo de estas cuestiones:

Solian antes de agora, (y avn muchos oy dia) escrivir de abajo hazia arria, poniendo el primer renglon hazia la mano izquierda (Ezguerra, $1747=1663:$ fol. 1).

Pero ya a principios del S. XVII de Morga describe la forma en que los pobladores de las Islas Filipinas escribían a la llegada de los españoles:

El orden de escribir, era en cañas, y ya en papel, començando los renglones, de la mano derecha a la izquierda, a la usanza arábiga; escriben en esta lengua casi todos los naturales, así ombres como mugeres, y muy pocas ay que no la escriban muy bien, y con propiedad (Morga, 1609: 274).

Más detallado es el comentario sobre la organización de los caracteres que encontramos en la Ortografía de Andrés de Castro que, además, incluye la comparación con la del chino y la del japonés:

El modo y forma de tirar los renglones, es de abaxo para arriba en lineas perpendiculares, poniendo el primer renglon ala mano izquierda, y el ultimo ala derecha: al contrario delos Chinas y Japones que siempre escriven de arriba para abaxo. Pero yo no sigo aqui en mi cartila este méthodo antiguo [...] Tampoco era cortesia escrivir en el respado de la Oja: sino que todo el asumpto lo havian de concluir en el anverso, y cara principal dela foxa, ó tabla; y sino alcanzava una, lo escrivian en muchas. que todo esto huele a mucha antigüedad (Castro, 1776: 63).

Hace, además, referencia a las apreciaciones sobre la presencia de dos rayas para indicar los límites entre dicciones, explicación que también encontramos en las gramáticas de Gaspar de San Agustín y de Ortiz. Castro señala, también, una serie de términos tagalos relacionados tanto con aspectos gráficos (el nombre de las letras y de los signos de puntuación, que también aparecen en otras gramáticas) como con diversos tipos de documentos:

los ladinos distinguen bien su escritura, con puntos, comas, y rayas, a manera de libros de solfa. Alas comas Ilaman bantas: alas virgulillas dichas; corlít. Ala pluma de acero, ò estilo ferreo conque escrivian en ojas de palma, Tablas, y piedras, Ilama Panulas a la Carta misiva, paralang sulat. A qualquiera escritura, sulat Al escriviente, manusulat. Al sello, Panala. Al Lector Tagabasa. Ala Cathedra, Basahan, \&c.

2, Ala primera letra del Abecedario Ilaman $A a$ : a la segunda Baba, a la tercera, Caca; a la quarta Dada; a la quinta ii, ala sexta, Gaga; a la septima, Haha a la octava, Lala; a la nona, Mama; a la Decima Nana; ala P, papa; a la S, sasa; ala T, tata, con V, consonante vava; a la $Y$, consonante, yaya; aquel su Caracter proprio llaman ng̃ang̃a y de esta manera a todas las demas. A deletrear llama baibai. Magbaibai cayó, deletread vosotros Magbasa cayó, leed. Magsisulat cayó, escribio todos (Castro, 1776: 62-63).

Antes de abordar la cuestión de la adaptación del alfabeto latino que realizaron los misioneros para representar las unidades fónicas de las lenguas filipinas, hemos de notar que en el tratamiento de los elementos fónicos se observa claramente el carácter contrastivo de las gramáticas y cobra especial relevancia la afirmación de Quilis sobre la gramática de Blancas de San José: se trata de "una gramática contrastiva española y tagala, de dificultades" (v. Quilis, 1982: 2; 1997: 26-27). Así lo asevera también Ridruejo en su análisis de la gramática de Benavente:

8 En este sentido, Quilis y Casado-Fresnillo (2008: 316 en nota $n^{\circ}$ 6) documentan al menos dos evidencias de que la escritura era también de abajo hacia arriba. La primera en la Historia de la provincia de Filipinas de la Compañía de Jesús de P. Chirino (1635?) y la segunda en el Diccionario geográfico, estadístico, histórico de las Islas Filipinas de M. Buzeta y F. Bravo (1850). 
al señalar la correspondencia de cada una de las grafías utilizadas al escribir esa lengua, Benavente presenta con detalle las peculiaridades fónicas del pampango, pues su finalidad no es sólo reflejar los valores del alfabeto indígena, que a fines del siglo XVII probablemente no era ya de utilidad, sino que, ante todo, se propone dar a sus lectores hispanos las reglas para pronunciar los textos pampangos [...]

Va examinando las equivalencias fónicas con el español e indica la transliteración de cada signo al alfabeto latino. Ahora bien, al establecer una comparación con la pronunciación del castellano, necesariamente aporta importantes observaciones sobre la fonética y la fonología del pampango (Ridruejo, 2005: 1831).

Esta afirmación puede hacerse extensiva a cualquiera de las artes que analizamos en esta investigación. Además, también en la tradición portuguesa este tipo de obras presentan esta propiedad; precisamente, Carvalhão señala que se trata de una "gramática comparativa nascente" (Carvalhão Buescu, 1983: 34).

También se debe reconocer con Sueiro Justel que la forma en la que Blancas en su temprana arte trata las cuestiones fónicas es muy avanzada e implica que tanto el artígrafo como los aprendices a los que va dirigida la obra tienen conocimientos gramaticales, de la lengua española y del latín. La inmersión lingüística, señala, es un factor fundamental en esta concepción:

El considerar las diferencias de acentuación como sustancia de la misma lengua, ya que permiten a un mismo significante tener dos significados 9 , o prestar atención al orden y consecución de las palabras constituyen referencias didácticas muy avanzadas que transcienden el mero aprendizaje gramatical de una lengua y suponen dos cosas: por un lado que el estudioso, al que se le supone una cierta formación y —desde luego- el conocimiento de la lengua castellana, está ante una manual contrastivo [...] pero, por otro lado, el alumno, guiado por el arte y las reglas de Bancas de San José, habrá de enfrentarse a la tarea de escuchar, entender y hablar con los nativos (Sueiro Justel, 2002a: 231-252).

En definitiva, los misioneros abordan la tarea de aplicar el abecedario a la codificación de las lenguas filipinas utilizando para ello los mecanismos que ya estaban presentes en las descripciones de los idiomas vernáculos de Europa y de América. En la elaboración ya de las primeras gramáticas filipinas (y, previamente, amerindias), los religiosos cuentan con una escritura conocida que refleja, grosso modo, un sistema fónico del español similar al actual (Quilis y Casado Fresnillo, 2008: 322).

\section{La adopción y adaptación del alfabe- to latino. Puentes entre Europa, Améri- ca y Filipinas}

Ante la presencia en las lenguas amerindias y filipinas de nuevos sonidos y la ausencia de otros con respecto a las lenguas de referencia, pronto se darán cuenta los misioneros gramáticos de que les era muy conveniente adaptar el alfabeto latino para representar su pronunciación, ya que este era un sistema bien conocido por ellos. Como hemos dicho, las razones para asumir el uso de este sistema escritural y emprender su modificación son eminentemente prácticas.

Como ya había sucedido en Europa, esporádicamente hasta el Renacimiento y con mayor auge a partir de entonces, debido a los intentos de gramatización de las lenguas vernáculas, tomar esta decisión conlleva la necesidad de suplir

9 Entendemos aquí que este investigador identifica significante exclusivamente con la conformación de las unidades segmentales. No obstante, si aplicamos en sentido estricto el planteamiento saussiriano, cualquier cambio sea segmental o acentual supone un cambio en el significante si este conlleva un cambio en el significado. Por tanto, no se trata de que un mismo significante tenga un mismo o diverso significado, sino que nos encontramos ante significantes diferentes pero que presentan las mismas unidades fonológicas segmentales. 
de algún modo las carencias gráficas de un alfabeto acomodado para representar los sonidos de otra lengua, el latín. Esto no era fácil y, como reconoce Esteve para las lenguas europeas (concretamente el español),

el ideal de escritura alfabética pura es difícil de alcanzar. El origen de las voces y el uso llegan a perturbar esa pretendida relación inequívoca entre sonido de la lengua y letra [...] la escritura [...] se muestra reacia a prescindir de signos gráficos que son testimonios de una situación pasada, o a la creación de otros nuevos para indicar fonemas hasta entonces inexistentes, prefiriendo en estos casos la utilización de grafemas complejos, polivalentes y equivalentes (Esteve Serrano, 1982: 17).

En esta empresa de adaptación expandirán el sistema escritural europeo mediante el uso de dígrafos y signos diacríticos, fundamentalmente procedentes de la notación abreviada de la escritura y de la puntuación. Convenientemente explicadas, estas modificaciones les servirán para optimizar la capacidad de representación del alfabeto (re)utilizado para las lenguas de América y Filipinas.

No obstante, en un primer momento las nuevas unidades gráficas creadas, que surgían a partir de otras existentes, no constituyeron elementos independientes de aquellas de las que se conformaban. Sabemos que, como señala Martínez Gavilán, todavía en las gramáticas españolas del s. XVII se repetía el abecedario latino, subordinando las grafías que representaban los sonidos nuevos que habían surgido en la evolución del latín al castellano a otros que pertenecían canónicamente al alfabeto clásico (v. Martínez Gavilán, 1983: 97 y ss.). De un modo similar se aborda en las gramáticas misionero-coloniales aquellas nuevas grafías, o grafías modificadas, que surgen como signo de los sonidos ausentes en las lenguas de referencia. Sirva de ejemplo el siguiente fragmento en el que se vinculan los fonemas /g/ y el / $\mathrm{\eta} /$ a través de sus representaciones gráficas en las artes tagalas:
ESTA LENGVA Tiene dos .g. Ia vna recia y clara como la nuestra [...] otra tienen gangosa en cuya pronunciacion (pues por momentos se ha de oyr) me remito a los mismos naturales. En lo que toca a la escritura para q[ue] se differencie dela otra, siempre se le antepone inmediatamente la letra .n. por q[ue] la mesma pronunciacion parece pedillo pero por q[ue] la otra .g. también puede tener y tiene algunas vezes.$n$. ante si, sele pone a esta gangosa vna señal encima q[ue] en este libro sera desta manera. g̃ (San José, 1610: 4).

Este procedimiento de expansión del alfabeto se constata ya en los inicios de la gramatización de las lenguas amerindias, incluso antes de su codificación gramatical (la primera gramática es el Arte Mexiana de fray Andrés de Olmos [1547]); así lo refiere Hernández de León cuando afirma que "en las primeras décadas de vida de la Nueva España el náhuatl se redujo a lengua escrita con el alfabeto latino y con una grafía propia que serviría de soporte a documentos de toda índole. Tal logro, que precedió a la codificación gramatical, comenzó en 1523 en Tezcoco con fray Pedro de Gante" (Hernández de León, 1997: 213-214).

Y es que la ortografía ha tenido una gran importancia siempre en la enseñanza de la lengua, sobre todo en el aprendizaje de la lectura y de la escritura. Así, "el porvenir de cualquier sistema ortográfico depende, pues, de la aceptación general y constante del mismo en los distintos niveles educativos durante varias generaciones consecutivas" (Esteve Serrano, 1982: 13). En efecto, una muestra evidente de ello es el peso que tuvo la educación en el abandono del silabario tradicional filipino. Recordemos cómo, al referirse a la imposición del alfabeto latino, Oyanguren señala en su gramática que los misioneros "ayudan [a la imposición de las letras góticas] con incessante desvelo, manteniendo en cada Pueblo su Escuela" (Oyanguren, 1742: 3-4).

Muy pronto los religiosos tienen conciencia del problema pedagógico que suponía la acepta- 
ción de los sistemas de escritura propios de los indígenas cuando la finalidad de sus gramáticas era la enseñanza de la lengua del modo más eficaz y rápido, con la mirada puesta en la evangelización. La representación gráfica de los sonidos de las lenguas que codifican se convierte entonces en una preocupación de primer nivel y acuden a la reutilización del sistema de escritura que conocen: el latino.

Las razones prácticas de su elección son evidentes. Por un lado, el sistema europeo les permitía representar los sonidos a través de un conjunto de unidades sincréticas conformadas de grafía y sonido, concepción similar a la littera de la tradición grecolatina, muy bien conocido por los religiosos que llegaban a evangelizar las nuevas tierras. Esta circunstancia permitía eludir el aprendizaje de un código grafemático diferente.

Por otro lado, las unidades de este alfabeto ya poseían una relación "unívoca”, con matices, con los sonidos del castellano y del latín. Unida a la subespecificación fónica en el tratamiento del plano de la expresión de las lenguas indígenas (Calvo Pérez, 2005: 153-154), esta última característica eximía a los artígrafos de acudir a complejas descripciones del componente fónico de las lenguas sometidas a arte. La explicación quedaba reservada (y reducida) a especificar el modo en que se pronunciaban aquellas unidades que, 0 bien no formaban parte del sistema castellano o latino pero que estaban presentes en las lenguas descritas, o necesitaban un ajuste para salvar la distancia fonética entre las realizaciones de la unidad invariante que el grafema representaba en castellano y las que debía representar en aquellas. Como muy acertadamente señala Suárez Roca, esto supone en el aprendiz el conocimiento no sólo de las características fónicas del español de la época sino también de esta correlación entre sonido y grafía (Suárez Roca, 1992: 84).

Así pues, la observación de Abercrombie de que "the Roman alphabet did well enough for La- tin [...] but it was not so satisfactory for the European vernaculars which later took it over" (1981: 207) es aplicable también a la situación con la que se encuentran los gramáticos misioneros.

Aunque nuestros artígrafos continúan ciñéndose a la tradición europea previa, reconocen las semejanzas y diferencias fónicas entre las lenguas que describen y las suyas propias mediante el uso los caracteres latinos. Su capacidad de observación muy pronto les llevará a reflexionar con naturalidad sobre el hecho de que las lenguas difieren en el plano fónico y tomarán la adecuación unidad fónica-figura como principio para la práctica. En definitiva, usan las letras teniendo en cuenta la sustancia fónica que les corresponde en español o latín y las adaptan a las nuevas realidades. No obstante, la adecuación no se producirá de forma totalmente consistente.

En este sentido, son varias las gramáticas analizadas para este trabajo que contienen explicaciones de las equivalencias representacionales de las letras del alfabeto latino aplicadas a la lengua filipina y en relación con su valor en la lengua castellana; además, elaborarán tablas en las que se establecen las paralelismos fónicográficos entre el sistema escritural filipino previo y el alfabeto latino (aspecto que pudo verse en la ilustración 1). Ejemplo de la descripción que realizan estos gramáticos de las correspondencias sonidos y letras con el alfabeto latino podría ser la que citamos a continuación:

No se trata de los caracteres Tagalos, porque es ya raro el Indio que los sabe leer, y rarissimo el que los sabe escribir. En los nuestros Castellanos leen ya y escriben todos. Diez y siete son las letras Tagalas. Las catorce son consonantes (y entre ellas lo son la y griega, y la $V$ de corazón que Ilamamos) y las tres Vocales [...] No tienen F, pero la suplen con la P; y assi para decir Confessar, dicen Conpisal. Ni LL para decir cavallo, dicen Cabayo, porque la suplen con la y. Ni tienen X, ni Z, ni J, suplenlas con la S, y assi dicen Sabon, por Xabon; sapato por zapato, y Suan por Juan. La que pro- 
nuncian como J es la $\mathrm{H}$, y assi Hali se ha de pronunciar como Jali (Totanes, 1745: 1-2).

En el caso concreto de Filipinas, los religiosos son además conscientes de que la adaptación no es perfecta y de que esta puede generar errores que no ocurrían con el silabario. Veamos dos ejemplos de lo que decimos. En ellos se hace referencia, entre otras cosas, a pares de palabras, como olol 'llenar' frente a ol-ol 'loco', que se distinguen perfectamente cuando están escritas en el sistema originario de las islas pero que necesitan de una marca especial en su transliteración al latino. La relación que existe entre aquello a lo que se están refiriendo y el silabario se antoja clara, ya que junto a cada palabra aparece su transcripción en el sistema escritural filipino (baibayin):

TAMBIEN les proviene muchas veces la diferencia a las palabras de dezirse con vayaon que ellos escriuen [carácter del silabario] o sin el [...] Lo qual se deue advertir para pronunciallos bien, porque sino es vayaon [carácter del silabario] sino q[ue] una vocal se sigue a otra: ha de ser aquella primera cortada breuemente, de manera que parezca deterner el aliento en ella vn poco. Pero con el vayaon ha de ser seguido y como encogiendo vn poco los labios. Como tambien consiste muchas vezes la diferencia en atar y juntar la consonante con la vocal siguiente o pronunciallas apartadas y cortada la vocal de la consonante que le precede (San José, 1610: 300).

Infinitas palabras se equivocan en nuestro escribir, que en caracteres tagalos se distinguen (San Agustín, 1787=1703: 152).

Con esta situación, el establecimiento de las correlaciones fónicas ha de completarse con la explicación de las diferencias encontradas. Como hemos dicho, en aquellos casos en que documentan sonidos que no se corresponden con ninguno de los de su lengua materna proponen generalmente dígrafos o la utilización de signos diacríticos.

Estas estrategias no son exclusivas de los misioneros gramáticos; la utilización de estas técnicas en la codificación de sonidos nuevos es común en la historia de los alfabetos. Este es, por ejemplo, el caso de la adaptación del fenicio al griego o los numerosos intentos de elaboración de abecés para la representación fónica de las lenguas europeas. Lo mismo podría decirse del uso de diacríticos u otras marcas como las mayúsculas (v. por ejemplo Abercrombie, 1981).

En esta época, como argumenta Calvo Pérez (2005: 138-139), aunque además del latino existían otros alfabetos disponibles para la representación gráfica del componente fónico de las lenguas amerindias, como el hebreo, el árabe o el griego, será aquel el que adopten los misioneros europeos, puesto que con él habían aprendido a escribir sus propias lenguas maternas.

A esta poderosa razón hemos de añadir que este era el sistema gráfico de la lengua de la Iglesia Católica, de la que ellos mismos eran ministros, y en el que, además, estaban escritas las gramáticas que servirán de modelo para la gramatización de las lenguas indígenas.

Por otro lado, probablemente no fueran una razón baladí las restricciones de la imprenta relacionadas con la dificultad que entrañaba modificar o montar nuevos tipos. Véase, por ejemplo, lo que dice al respecto Luís de Valdivia en su Arte y gramática general de la lengva que corre en todo el Reyno de Chile (1606):

lo qual ha sido dificil para la Imprenta por no auer moldes destas figuras, y auer sido menester hazerlos nueuos, por ser esta letra la mas frequentada en esta lengua en todas las terceras personas duales y plurales (apud Calvo Pérez, 2005: 158).

Con los datos que nos aportan las gramáticas sobre la adaptación del alfabeto latino a las lenguas descritas y partiendo del hecho de que la elección de determinados diacríticos o dígrafos no es azarosa, podemos concluir que, en un sentido estrictamente fónico, los gramáticos son conscientes, aun sin formularlo explícita- 
mente, de la semejanza que puede darse entre las unidades fónicas del castellano y las de las lenguas que describen y de las diferencias y ausencias que son capaces de identificar por contraste entre ellas.

En la mayor parte de los casos, los misioneros prefieren mantener la grafía del sonido al que se parecen antes de proponer una nueva; a esta pueden añadir otra para formar un dígrafo cuyo referente fónico aislado se corresponde en alguno de sus rasgos con el efecto sonoro del sonido descrito. En definitiva se trata de la grafía de una prolación que adopta el punto o modo de articulación (en ocasiones, como en las glotales, la mayor tensión articulatoria mediante la duplicación) del sonido que representa el grafema con el que se forma. Esta particular manera de denotar la variación en el punto y/o modo de articulación no es novedosa, puesto que ya la encontramos en el Anónimo Islandés (S. XII).

Ya en las gramáticas misioneras americanas (v. Smith-Stark, 2005), encontramos esta estrategia vinculada al modo de articulación. Quizá el ejemplo más interesante podría ser la utilización de 〈h〉 como índice de la aspiración para algunas lenguas amerindias. Es evidente que, ante sonidos articulatoriamente y perceptivamente similares, los autores establecen el contraste entre, por ejemplo, plosivas no aspiradas $\langle p, t, k\rangle$ y las aspiradas <ph, th, kh, qhu, thz, ths $\rangle$.

Con respecto al cambio de punto de articulación que tiene como resultado sonidos semejantes que se diferencian por este rasgo, documentamos en las gramáticas de América estrategias como la geminación consonántica para indicar la glotalización, la presencia o inversión de la grafía para señalar el carácter retroflejo o el uso del dígrafo <ae> para marcar la vocal media.
Pero el caso más interesante para este trabajo centrado en las obras gramaticales realizadas en filipinas, aunque también se atestigua en las artes amerindias, es la estrategia que utilizaron para la representación gráfica de la consonante gangosa (la nasal velar). Este procedimiento puede constatarse en la definición que de ella hace ya el padre Blancas (1610) o en la que citamos a continuación, procedente de la gramática pangasinán de Andrés López:

$L A G$, gangosa es vna consonante compuesta de $n$, y g, la qual se escribe desta suerte $n \tilde{g}$, y en los caracteres tiene el suyo particular con que la distinguen de la ordinaria [...] Digo pues que el modo de pronunciar la tal letra, no esta en echar el aliento por las narices, que desso se rie[n] los indios, si no en que la $n$, y la g se pronuncie, como si fuera vna sola consonante debaxo de vn punto, de suerte, que si hubiere de herir a la vocal que le sigue, en ninguna manera se pronuncie la n con la vocal que estubiere antes, sino que $n, y g$ caigan juntas sobre la vocal que se sigue (López, 1690: fol. 3 r y v).

Se trata de una nasal cuya característica fundamental en su pronunicación no está en la expulsión del aire por las fosas nasales sino en que tenga el punto de articulación retrasado de la [g]. Es evidente que los españoles percibían esta consonante como nasal y se afanaban en expulsar el aire por la nariz, lo que causa risa en los naturales ${ }^{10}$.

Lo que sí es relevante para los gramáticos misioneros es el punto de articulación más retrasado [ $\eta$ ] que el de cualquiera de las realizaciones de las unidades nasales con función significativa del castellano. Este lugar de articulación se relaciona con el que tiene el sonido $[\mathrm{g}] \mathrm{o}[\mathrm{\gamma}]$ en español, y de ahí la amalgama que proponen estos religiosos. Probablemente, sin ser conscientes

10 Hoy sabemos que la percepción de la nasalidad obedece a una suma de factores y no solo a la salida del aire por la nariz como, por ejemplo, el grado de abertura o cierre del puerto velofaríngeo en relación con el tamaño del resonador posterior de la cavidad oral, del punto de articulación de la consonante, etc. Incluso la expulsión del aire por la nariz es innecesaria para producir un sonido nasal, como se constata, por ejemplo, cuando estamos acatarrados. 
de ello, apelan, a través de la escritura, a una concepción similar a la del rasgo fonético vinculado al punto de articulación.

Esta diferencia entre una y otra $\langle\mathrm{g}\rangle$, que en ocasiones se denomina guturación, se marca mediante la presencia de los dígrafos $\langle n g$, n $\tilde{g}\rangle$ o del grafema $\langle\tilde{g}\rangle$, si bien distinguirán con claridad la copresencia en una agrupación heterosilábica de $[n+g]\langle n g\rangle$ del dígrafo que señala un solo sonido nasal velar. El carácter nasal aparece marcado por la $\langle\mathrm{n}\rangle \mathrm{y} / \mathrm{o}$ por la virgulilla, en tanto que el punto de articulación velar de la consonante se representa mediante la grafía de una consonante velar sonora del español $[\mathrm{g} / \mathrm{Y}]\langle\mathrm{g}\rangle$; la primera aporta, por tanto, el rasgo [nasal], y la segunda, el [velar].

Como vemos, a una letra del alfabeto latino se la relaciona con dos sonidos; para diferenciar uno de otro se le añaden otras consonantes, formando un dígrafo, y/o signos diacríticos. Similar es el modo de tratar en las gramáticas peninsulares de la época las grafías 〈II, ñ, rr, ch〉 (v. Martínez Gavilán, 1983).

Parece pues que los principios rectores de los intentos de modificación del alfabeto latino, al igual que los señalados en el ámbito europeo, son cuatro: 1) la ambigüedad debía ser evitada, restringiendo cada símbolo a un sonido o sílaba y procurando que cada sonido estuviera representado solamente por una grafía, 2) los símbolos tendrían que ser simples pero con formas claramente distinguibles, 3) la transcripción debe poder ser pronunciada, es decir, debe existir una clara relación sonido-grafema y 4) el sistema tiene que ser expandible (restricción debida al intento de construir un alfabeto virtualmente válido para representar los sonidos de todas las lenguas) (v. Kemp, 1994)
De la capacidad de extensionabilidad del alfabeto hacen uso con gran pericia las artes misionero-coloniales americanas y filipinas. No obstante, esto no preocupaba a nuestros gramáticos, habida cuenta de que sólo les interesaba la adaptación con un fin muy concreto: la descripción con intención práctica de una lengua particular.

Pero, además, a estas líneas generales debemos añadir aquel principio que resulta del intento de resolver el problema de la distancia entre los sonidos asociados a las grafías en la lengua materna de los misioneros y aquellos que van a representar y que proceden de la lengua que se disponen a describir. En este sentido, la descripción del componente fónico de las lenguas se rige, en opinión de Calvo Pérez (2005), por el criterio de mínimo esfuerzo. Así, la adaptación del alfabeto y la descripción fónico-ortográfica en estos términos les llevará a desarrollar sistemas ortofónicos en los que se da una subespecificación; que determinados fenómenos fónicos no se reflejen en la ortografía,

en cierto modo, es un principio asumible: puesto que la diversidad del habla sólo puede ser captada en el uso (el otro gran eslogan misionero), evítense las complicaciones que harían rechazar a los aprendices del arte la ortografía de las lenguas indígenas y aproxímese ésta todo lo posible a la de las lenguas maternas de los misioneros y al latín, ${ }^{11}$ porque entonces gran parte del camino estará ya recorrido [...] hay hipodistinción tanto fónica como ortográfica, aunque por distintas razones, unas teóricas y otras prácticas (Calvo Pérez, 2005: 153-154).

El propio Blancas prefiere la explicación de las equivalencias a la adición de signos o marcas a las letras conocidas, probablemente debido a dificultades de imprenta:

11 Sin embargo, a principios del s. XVII y según este mismo investigador (en ese mismo trabajo), en las gramáticas del aimara y, especialmente, en el Vocabulario de la lengua Aymara de Bertonio (1612) predomina un intento de ajustar al máximo escritura-pronunciación de modo que la hipo-diferenciación deja de ser un ideal. Para ello, el misionero usa dos estrategias: 1) la duplicación de letras y 2) el uso de letras a las que el añadido de otra modifica su pronunciación. 
SIEMPRE que se viere esta letra $V$ en palabras Tagalas, no se lea consonante q hiera la Vocal siguiente, sino liquida, al modo que ponuncia el Español ygual: porque en Tagalo no ay v ni u que hiera, que la b haze esso y la $v[. .$.$] se ha de decir$ como agora habemos dicho. V.G. tavo, y assi no la escriuiremos jamás con esta u sino con esta $v$ (San José, 1610: 4).

Nótese cómo la simplificación y reserva de una letra para cada sonido es un claro intento de evitar confusiones; así, se prefiere la grafía $\langle b\rangle$ para el sonido con rasgo consonántico y la $\langle\mathrm{V}\rangle$ para el líquido (léase "líquido" en el sentido de la tradición grecolatina).

Finalmente, ha de hacerse referencia a una cuestión especialmente relevante en el proceso de enseñanza-aprendizaje de una lengua: el acento ${ }^{12}$. También se utilizan abreviaturas para señalar la acentuación en las gramáticas misioneras. Estas tienen un marcado carácter pedagógico y evitan el añadido de diacríticos a las letras. En el siguiente ejemplo, Blancas se refiere a este fenómeno prosódico y propone dos términos, procedentes de la tradición grecolatina, para señalar el lugar del acento:

Pen. Prod. Quiere decir penúltima producto que es decir, que la syllaba que antecede a la ultima sea larga y espaciosa en aquella palabra cuyo accento se declara. Pen corr., quiere decir, penúltima correpta, que es decir, que no se ponga el acento en la penúltima sino en la precedente a la penúltima: como spiritu, que no nos detenemos en el ri, sino en el pi (San José, 1610: 1).

También en relación con el acento, Totanes argumenta como Blancas, pero especifica la teoría que subyace al modo de la tradición gramatical latina (probablemente Blancas da por supuesto este conocimiento y solo sintió la necesidad de señalar el nombre técnico):

Baste aquí decir que son dos los Acentos, el uno es largo, y se denota en el Vocabulario con esta cifra, pc. A quien Ilama el tagalog Surlàc. El otro es breve, y se denota con esta pp y llaman Banáyar. A los quales, por la brevedad, y facilidad mayor, se acentuaràn en este Arte como en el Latin y en el Castellano se acentua; al largo en la última, y al breve en la penúltima ó antepenúltima (Totanes, 1745: 4).

Observemos cómo Totanes, a diferencia de Blancas, modifica la teoría latina sobre el acento para adaptarla a la realidad de la lengua, aunque mantiene el molde general de la acentuación. Se trata, sin duda, de lo que denominamos el uso de los conceptos clásicos mediante su aplicación en función de determinadas propiedades presentes y otras ausentes (v. Cuevas Alonso, 2011: caps. 2 y 3). Si bien ambas cifras notan la cantidad de la penúltima (penultima producta/correpta), que en latín determinaba el acento, Totanes toma como referencia no la penúltima sino la última. No sólo no se extraña de la presencia de oxítonas, que ya conocía por el español, sino que no parece encontrar contradicción alguna en la aplicación de la teoría latina del acento a esta nueva realidad. De este modo, explica, si el acento es largo, la palabra es oxítona y, si es breve, paroxítona o proparoxítona.

\section{Conclusiones}

En algunas artes y ortografías realizadas por misioneros españoles en Filipinas se conservan referencias al sistema escritural de carácter silábico previo a su llegada. En ellas se señala el valor de cada una de las grafías con respecto al alfabeto latino y encontramos, incluso, explicaciones sobre la dirección de la escritura y la dimensión material. No obstante, en muchas se constata el progresivo olvido al que se vio sometido el silabario en favor del alfabeto latino, siendo la educación la gran aliada en su adopción y generalización. 
Es obvio que la necesidad de un rápido aprendizaje cuyo fin es la comunicación, fundamentalmente centrada en la transmisión de los textos sagrados y de la doctrina de la Iglesia, debía descansar en un sistema de representación gráfica conocido por los misioneros y eminentemente fónico (o fonológico, si se prefiere), en lugar de enfrentar a los aprendices a las dificultades que entrañaría la lectura y aprendizaje en un alfabeto extraño.

Este modo de proceder no es, tampoco, exclusivo de los misioneros. La búsqueda de un alfabeto adecuado con finalidad didáctica es uno de los objetivos perseguidos, como señala Kelly (2003), durante todo el s. XVI. En su opinión, "need was felt for revised scripts to serve as more efficient teaching media for diplomats, merchants, and travellers" (Kelly, 2003: 303). A este objetivo se unirá también el de aquellos que investigan cómo enseñar a hablar a los sordos. Estos realizarán descripciones muy detalladas tanto de los articuladores como de los fenómenos fónicos ${ }^{13}$.

Los misioneros españoles en Filipinas, conocedores de la experiencia americana, no dudaron de la conveniencia de reemplazar el sistema de representación gráfica silábico que se encontraron, por muy bien establecido que estuviese. No obstante, algunos abogan porque el misionero conozca y aprenda el silabario, que, como se dijo, tenía algunas ventajas en la interpretación de algunos aspectos fónicos de las lenguas filipinas con respecto al alfabeto latino. Sin embargo, pronto se percataron de que, por su gran diferencia con este, aquel entorpecía el necesariamente rápido aprendizaje de la lengua por parte de los nuevos religiosos. Como había sucedido en Hispanoamérica, esta situación les hace optar por la adaptación del abecedario para representar los sonidos de las lenguas de Filipinas.
En definitiva, en el caso de las gramáticas de este archipiélago asiático tenemos una completa adaptación del alfabeto latino a la realidad lingüística y nos encontramos con descripciones contrastivas de las equivalencias, ausencias y novedades fónicas entre los signos de representación adoptados del alfabeto latino (también de los del silabario) para la lengua descrita y los de las lenguas de referencia del misionero: el latín y el castellano. Y no está de más señalar de nuevo que los autores de las gramáticas utilizadas para esta investigación parten de la experiencia previa en América y de los conceptos de la tradición grecolatina, lo que les permite también realizar contrastes de las características silábico-fonéticas entre las lenguas filipinas/amerindias y las de referencia.

\section{Bibliografía}

\subsection{Fuentes primarias}

Benavente, Álvaro de, c. 1699: Arte y Vocabulario de lengua pampanga compuesto por fray Alvaro de Benavente del orden de N. P. S. Augustin obispo electo ascalonense, vicario apostolico de la provincia de kiang si en el reyno de la China. [Transcripción y traducción al inglés de Fr. Edilberto V. Santos, Manila: Holy Angel University Press, 2005].

Bergaño, Diego, 1736=1729: Arte de la lengua Pampanga, compuesto por el R. P. Lector Fr. Diego Bergaño, de el Orden de los Hermitaños de N. P. S. Agustin, Examinador Synodal de este Arzobispado de Manila, y Prior del Convento de Bacolor. Nuevamente añadido, emmendado, y reducido à methodo mas claro, por el mismo autor, siendo actual Provincial de esta su Provincia de el Santissimo Nombre de lesus. Reinpresso con las Licencias necessarias, en el Convento de Nra. Señora de Loreto de el Pueblo de Sampaloc. Año de 1736.

13 Nos referimos, por ejemplo, al libro de Juan Pablo Bonet, Reducción de las letras y arte para enseñar a hablar los mudos (1620). 
CASTRO, Pedro Andrés de, 1776: Ortografia y Reglas de la Lengua Tagalog acomodadas a sus propios caracteres por D. Pedro Andres de Castro. Manila 1776. [Reproducción del MS. ordenada por Antonio Graíño según el ejemplar de su Colección Hispano-Ultramarina en la Colección Monografías de la España Colonial, Madrid: Librería General de Victoriano Suárez, 1930].

CoRonel, Francisco, c. 1621: Arte y reglas de la lengua Pampanga: Compuesto por el Padre Predicador Fr. Francisco Coronel del Orden de N. P. S. Agustín y Prior Ministro del Convento de Macabebe. Dedicado al Dulcissimo Nombre de Jesus. Acabado el año 1621. [Transcripción, traducción y anotación de Fr. Edilberto V. Santos, Manila: Holy Angel University Press, 2005].

EzGuerRa, Domingo, 1747=1663: Arte de la Lengua Bisaya de la Provincia de Leyte compvesta por el P. Domingo Ezgverra de la Compañia de IESVS, su Vice Provincial en las Provincias de Pintados, y Rector de la Residencia de Carigara. Tiene enxeridas algvnas advertencias de la lengua de Zebù, y Bool: Ias de Zebù señaladas con la letra $Z$, y las de Bool con la letra B, y juntamente algunos adverbios con su uso para hablar con elegacia. Reimpressa. Con las Lic. necessarias en Manila en la Imp. de la Compañia de lesus, por D Nicolas de la Cruz Bagay. Años de 1747.

López, Andrés, 1690: Arte de la lengva de Pangasinan Compvesta por el R. P. Fr. Andres Lopez del Orden de Predicadores. Dedicada al M. R. P. Fr. Bartholome Marron de dicha Orden. Calificador del S. Officio, y Provincial que á sido de esta Prouincia del Santissimo Rosario de Philipinas. Con las Licencias Ordinarias en el Collegio, y Vniversidad de Santo Thomas de Aquino. Por el Capitán D. Gaspar de los Reyes. Año de 1690.

LóPEz, Francisco, 1792=1628: Compendio, y Methodo dela Svma de las Reglas del Arte del Ydioma Ylocano, qie a los principios del siglo passado compuso el M. R. P. Fray Francisco Lopez del Sagrado Orden de N. G.P. S. Augustin. Yà los ultimos de este Siglo apunto otro Religioso de la misma Orden: el M. R. P. Predicador Fray Fernando Rey. Examinador Synodal de este Obispado, y Cura en propiedad del Pueblo de Barac para alivio y menos embrazo de los Religiosos que empiezan à aprehender el Idioma para ser Ministros.

Magdalena, Agustín de la, 1679: Arte dela Lengua Tagala, sacado de diversos artes por Fr. Avgvstin de la Magdalena; Religioso Descalço del Señors. Diego. Procurador General de la Provincia de S. Gregorio de las Islas Philipinas. Con Licencia, Por Francisco Rodriguez Lupercio, de 1679.

Méntrida, Alonso, 1818=1637: Arte de la lengua Bisaya-Hiliguayna de la Isla de Panay Compuesto por Fr. Alonso de Mentrida de la Orden de San Augustin. Impreso en Manila en la Imprenta de Don Manuel Memije por Don Anastacio Gonzaga. Año de 1818.

Méntrida, Alonso, 1884=1637: Arte de la lengua Bisaya-Hiligayna de la Isla de Panay Compuesto por el M. R. P. Fr. Alonso de Méntrida de la Orden de N.P. S. Agustín corregido y aumentado por el M. R. P. José Aparicio de la misma orden. Tambobong. Pequeña Litografía del Asilo de Huérfanos de Nuestra Señora de la Consolación.

Ortiz, Tomás, 1740: Arte y Reglas de la Lengva Tagala. Por el M. R. P. Lect. Fr. Thomas Ortiz Ex-Provincial de su Província del Smo. Nombre de JESVS del Orden de N. P. S. Agustin en eftas Islas Philipínas, y Prior de el Convento de Nra S. de Guadalupe. Dedicado al Smo. y Dulcisimo Nombre de JESVS. Viderunt omnes populi gloriam nominis ejus. Omnia in Nomine Dni. N. Jesu Christi, facite. Impresso con las Licencias necessarias en el Convento de Nra Señora de Loreto en el Pueblo de Sampaloc. Año de 1740.

Oyanguren de Santa Inés, Melchor, 1742: Tagalysmo Elucidado, y reducido (en lo possible) á la Latinidad de Nebrija Con su Syntaxis, Tropos, Prosodia, Passiones, \&c. y con la alusion, que en su uso, y composicion, tiene con el Dialecto Chinico Mandarin, con las Lenguas Hebrea, y Griega. Para ali- 
vio de los RR. Padres Missioneros Appostolicos, que passan à aquellas Missiones, y Exaltacion de Nra Sta. Fee, Catholica, Apostolica Romana. Compuesto por N. H. Fr. Melchor Oyanguren de Santa Ynès, Religios o Descalzo del Seraphico instituto, Predicador, y Missionero Appostolico Comiss. Proâl. de la Mission. Debajo de la proteccion del S. D. Pedro Anselmo Sanchez de Tagle, Inquisidor Mayor en los Reynos de es ta Nueva España, y Islas adjacentes, \&c. Con Licencia en Mexico: En la imprenta de D. Francisco Xavier Sanchez. En la Calle de S. Francis co. Año de 1742.

Totanes, Sebastián de, 1745: Arte de la lengua tagala, y manual tagalog, para la administración de los Santos Sacramentos, que de orden de sus superiores compuso Fray Sebastián de Totanes, Hijo de la apostolica, y Seraphica Provincia de S. Gregorio Magno, de Religiosos Descalzos de la Regular, y mas estrecha Observancia de Nuestro Seraphico Padre San Francisco de las Islas Philipinas, Para alivio de los religiosos de la misma Santa Provincia, que de nuevo se dedican à aprender este Idioma, y son Principiantes en la Administracion Espiritual de las Almas. Impresso en la Imprenta del vso de dicha Santa Provincia, sita en el Convento de Nra. Señora de Loreto en el Pueblo de Sãpaloc Extra-muros de la Ciudad de Manila, Año de 1745.

San Agustín, Andrés de, 1795: Arte de la Lengua Bicol para la Enseñanza de este Idioma en la Provincia de Camarines. Dispuesto, y ordenado por Nuestro Hermano Fr. Andres de San Agustin, Predicador, Guardian del Convento de de San Phelipe, y Santiago del Pueblo de Minalabag, y Comissario Provincial, que fue de dicha Provincia. Segunda ves Reimpresso con las Licencias necessarias en el Convento de Nuestra Señora de Loreto del Pueblo de Sampaloc por el Hermano Pedro Arguelles de la Concepcion. Año de 1795.

San Agustín, Gaspar de, 1787=1703: Compendio de la Arte de la Lengua Tagala. Por el Padre Fr. Gasparde San Avgvstin, Religioso de el mismo Orden, Comissario de el Santo Oficio, Visitador de esta Provincia de Philipinas, y Prior de el Convento de Tambobong. (Año 1703.) Segvnda Impression. Con las Licencias necessarias en la Imprenta de Nuestra Señora de Loreto del Pueblo de SampaIoc: Año de 1787.

San José, Francisco de = Blancas de San José, 1610: Arte y reglas de la lengua tagala. Por el Padre.F. Fray Francisco de.S. Ioseph de la Orden de.S. Domingo Predicador General en la Prouincia de.N. Señora del Rosario de las Islas Filipinas. En el Partido de Bataan. Por Thomas Pinpin Tagalo, Año de 1610. [Estudio y edición crítica de Antonio Quilis, Madrid: Ediciones de Cultura Hispánica. A.E.C.I. 1997].

\subsection{Bibliografía citada}

Abercrombie, D., 1965a: "Writing systems" en D. Abercrombie (ed.): Studies in phonetics and linguistics, Londres: Oxford University Press, 86-91.

Abercrombie, D., 1965b: "Forgotten Phoneticians" en D. Abercrombie (ed.): Studies in phonetics and linguistics, Londres: Oxford University Press, 45-75. AberCROMBie, D., 1981: "Extending the Roman Alphabet: Some Ortrographic Experiments of the Past Four Centuries" en R. E. Asher y J. A. Henderson (eds.): Towards a History of Phonetics, Edinburgh: Edinburgh University Press, 207-224.

Acker, G. van, 1994/1995: "Dos alfabetos amerindios nacidos del diálogo entre dos mundos", Amerindia 19/20, 403-420.

Altman, C., 1999: "As gramáticas das 'linguas gerais' sul-americanas como um capítulo da historiografia lingüística ocidental" en M. Fernández Rodriguez, F. Garcia Gondar y N. Vazquez Veiga (eds.): Actas del I Congreso Internacional de la Sociedad Española de Historiografía Lingüística, Madrid: Arco/ Libros, 151-160.

Arzapalo Marín, R., 2005: "La representación escritural del maya de Yucatán desde la época prehispánica hasta la colonia. Proyecciones hacia el s. XXI" en O. Zwartjes y C. Altman (eds.): Missionary Linguistics II/Lingüística misionera II. Ortogra- 
phy and Phonology, vol. 109, Philadelphia: John Benjamins, 89-106.

Auroux, S., 1994: La révolution technologique de la grammatisation, Lieja: Mardaga.

Bertonio, L., 1612: Vocabulario de la lengua Aymara compuesto por el P. Ludovico Bertonio Italiano dela Compañía de lesus en la Provincia del Tiru, de las Indias Occidentales, Natural de la Roca contrada dela Marca de Ancona. Dedicado al illustrissimo y raeverendissimo Señor Don Fray Domingo Valderrama Centeno Maestro en sancta Theologia, Arçobispo, y primer Obispo dela Paz, del Consejo de su Magestad. Impresso enla casa de la Compañoa de Iesus de Oili Pueblo dela Provincia de Chiucuito. Por Francisco del Canto. 1612.

Borrero Barrera, M. ${ }^{a}$ J., 2002: "De cuando Europa descubrió América a través de su escritura”, Signo. Revista de Historia de la Cultura Escrita 9, 17-35.

Breva Claramonte, M., 2008: "El marco doctrinal de la tradición lingüística europea y los primeros misioneros de la Colonia”, Bulletin Hispanique 110 (1), 25-59.

Bustamante, J., 1987: "Las lenguas amerindias: una tradición española olvidada”, Histoire épistémologie Langage IX (2), 75-97.

Calvo Pérez, J., 2005: "Fonología y ortografía de las lenguas indígenas de América del Sur a la luz de los primeros misioneros gramáticos" en O. ZWARtjes y C. Altman (eds.): Missionary Linguistics II/Lingüística misionera II. Ortography and Phonology, vol. 109, Philadelphia: John Benjamins, 137-170.

Carvalmão Buescu, M. ${ }^{a}$ L., 1983: O estudo das línguas exóticas no século XVI, Lisboa: Biblioteca Breve Instituto de Cultura e Língua Portuguesa.

Cuevas Alonso, M., 2011: Ideas lingüísticas en las gramáticas misionero-coloniales de Filipinas (ss. XVII y XVIII). Tesis doctoral, Universidad de Vigo. Cuevas Alonso, M. (en preparación): "La reformulación del concepto de acento de la gramática grecolatina y española en las artes misioneras filipinas".

Díaz Rubio, E. y J. Bustamante García, 1986: "La alfabetización de la lengua nahuatl” en A. QUILIS y H. J. E. NIEDEREHE (eds.): The History of Linguistics in Spain, Philadelphia: John Benjamins, 189-211.

Esparza Torres, M. Á., (2007): "Nebrija y los modelos de los misioneros lingüistas del náhuatl” en O. Zwartjes, G. James y E. Ridruejo (eds.): Missionary Linguistics III/Lingüística misionera III. Morphology and Syntax. Selected papers from the Third and Fourth International Conferences on Missionary Linguistics, Hong-Kong/Macau, 12-15 March 2005, Valladolid, 8-11 March 2006, Vol. 111, Philadelphia: John Benjamins, 3-40.

Esparza Torres, M. Á., 2010: "Dimensiones de la lingüística misionera española” en C. Asunção, G. FERNANDES y M. Loureiro (eds.): Ideias Linguísticas na Península Ibérica (séc. XIV a séc. XIX), vol. I, Münster: Nodus Publikationen, 201-214.

Esteve Serrano, A., (1982): Estudios de teoría ortográfica del español, Murcia: Publicaciones del Departamento de Lingüística General y Crítica Literaria (Universidad de Murcia).

García Medall, J., 2010: "Los prólogos de la lexicografía Hispano-Filipina (1613-1914)" en C. Asunção, G. Fernandes y M. Loureiro (eds.): Ideias Linguísticas na Península Ibérica (séc. XIV a séc. XIX), vol. I, Münster: Nodus Publikationen, 303-314.

Guzmán Betancourt, I., 1997: "La lengua, ¿compañera del imperio? Destino de un 'presagio' nebrisense en la Nueva España” en I. Guzmán Betancourt y E. Nansen Díaz (eds.): Memoria del coloquio La obra de Antonio de Nebrija y su recepción en la Nueva España. Quince estudios nebrisenses, México: Instituto Nacional de Antropología e Historia, 23-37.

Hernandez de León-Portilla, A., 1997: "De la palabra hablada a la palabra escrita. Las primeras gramáticas del Náhuatl”, Estudios de cultura Náhuatl 27, 209-225.

Hernández de León-Portilla, A., 2007: "Misioneros 
gramáticos. Tradición clásica y modernidad mesoamericana" en Paradigmas de la palabra. Gramáticas indígenas de los siglos XVI, XVII, XVIII, Madrid: Turner, 37-58.

Horta Nunes, J., 1993: "Processus de litteralisation dans l'Arte de José de Anchieta”, Histoire épistémologie Langage 15 (2), 69-95.

Kelly, L. G., 2003: "History of the Field [Phonetics]" en W. J. Frawley (ed.): International Encyclopedia of Linguistics, Oxford: Oxford University Press, 302-306.

KemP, J. A., 1994: "Phonetics: Precursors of Modern Approaches" en R. E. Asher (ed.): The Encyclopedia of Language and Linguistics, Londres: Pergamon, 3102-3116.

Martinez Gavilán, M. a D., 1983: Las ideas fonéticas en la lingüística española del siglo xvii. Tesis doctoral, Facultad de Filosofía y Letras - Universidad de León.

Montolinía, T. de, 1541: Historia de los indios de la Nueva España.

Morga, A. de, 1609: Svcesos de las Islas Filipinas dirigido. a don Cristoval Gomez de Sandoual y Rijas, Duque de Cea. Por el doctor Antonio de Morga, Alcalde del Crimen, e la real Audiencia de la Nueva España, Consultor del Santo Oficio de la Inquisicion. En Mexico, en casa de Geronymo Balli. Año 1609

Moreno Fernández, F., 1994: "Antonio de Nebrija y la lexicografía americana del siglo XVI. A propósito del Lexicón de Fray Domingo de Santo Tomás", Voz y Letra $V(1), 79-104$.

NebrijA, E. A. de, 1492: Gramática Castellana, Salamanca. [Introducción y notas de M. Á. Esparza y R. Sarmiento, Madrid, Fundación Antonio de Nebrija, 1992].

Oesterreicher, W. y R. Schmidt-Riese, 1999: "Amerikanische Sparchenvielfalt und europüaische Grammatikkonzeption: Missionarslinguistik im
Epochenumbruch der Frühen Neuzeit" en B. ScHmidT-RIESE (ed.), Katechese, Sprache, Schrift, Stuttgart y Weimar: J. B. Metzler.

Phelan, J. L., 1959: The Hispanization of the Philippines. Spanish Aims and Filipino Responses. 15651700, Madison: University of Winsconsin Press.

Quilıs, A., 1982: "El Arte y Reglas de la lengua tagala", Nueva revista de Filología Hispánica XXXI (1), 1-24. Quilis, A., 1997: "Estudio" en Arte y Reglas de la Lengua Tagala (Francisco de San José), Madrid: Ediciones de Cultura Hispánica, Instituto de Cooperación Iberoamericana.

Quilis, A. y C. Casado-Fresnillo, 2008: La lengua española en Filipinas. Historia, situación actual. El chabacano. Antología de textos, Madrid: CSIC.

Ridruejo, E., 2005: "La descripción de los sonidos en las primeras gramáticas del pampango" en Filología y Lingüística. Estudios ofrecidos a Antonio Quilis, Vol. II, Madrid: CSIC/UNED/Universidad de Valladolid, 1830-1842.

Smith-Stark, T. C., 2005: "Phonological description in New Spain" en O. ZwartJes y C. Altman (eds.): Missionary Linguistics II/Lingüística misionera II. Ortography and Phonology, vol. 109, Philadelphia: John Benjamins, 3-64.

SuÁrez, M., 2007: "Paradigmas de la palabra" en Paradigmas de la palabra. Gramáticas indígenas de los siglos XVI, XVII, XVIII, Madrid: Turner, 4-36.

SuÁrez Roca, J. L., 1992: Lingüística misionera española, Oviedo: Pentalfa.

Sueiro Justel, J., 2002a: "Francisco Blancas de San José, pionero de la lingüísica española en Filipias" en I. Baez Montero y M. ${ }^{a}$ R. Pérez (eds.): Romeral. Estudios filológicos en homenaje a José Antonio Fernández Romero, Vigo: Universidad de Vigo, 231-252.

SueIRo Justel, J., 2002b: La política lingüística española en América y Filipinas (siglos XVI-XIX), Lugo: TrisTram. 
Sueiro Justel, J., 2002C: La enseñanza de idiomas en Filipinas (siglos XVI-XIX), Vol. 6, A Coruña: Toxosoutos.

Sueiro JustelL, J., 2002d: "Aspectos generales de la política lingüística española en América y Filipinas" en M. Á. Esparza Torres, B. Fernández Salgado y H. J. E. Niederehe (eds.): SEHL 2001. Estudios de Historiografía Lingüística. Actas del III Congreso Internacional de la Sociedad Española de Historiografía Lingüística. Vigo, 7-10 de febrero de 2001, Hamburg: Helmut Buske Verlag, 695-707.

Sueiro Justel, J., 2003: Historia de la lingüística española en filipinas (1580-1898), Lugo: Axac.

Swiggers, P. y S. Vanvolsem, 1987: "Les premières grammaires vernaculaires de l'Italien, de l'Espagnol et du Portugais", Histoire épistémologie Langage IX (1), 157-181.

Zimmermann, K., 2004: "La construcción del objeto de la historiografía de la Lingüística Misionera” en O. Zwartjes y E. Hovdhaugen (eds.): Missionary Linguistics/Lingüística Misionera, vol. 106, Philadelphia: John Benjamins, 7-32.

ZwartJes, O. (ed.), 2000: Las gramáticas misioneras de tradición hispánica (siglos XVI-XVII), Ámsterdam: Rodopi, 205-256. 